\title{
Conceptual Model for E-Banking System using Indigenous Biometric Technique
}

\author{
Omogbhemhe M.I. \\ Department of Mathematical \\ And Physical Sciences, \\ Samuel Adegboyega \\ University \\ Ogwa, Edo State Nigeria
}

\author{
Momodu I.B.A. \\ Department of Computer \\ Sciences \\ Ambrose Alli University, \\ Ekpoma, Edo State Nigeria
}

\author{
Sadiq F.I. \\ Faculty of Computing \\ University Teknologi \\ Malaysia \\ 81310 Skudai Johor Bahru \\ Malaysia
}

\begin{abstract}
The Central Bank of Nigeria (CBN) recently introduced the cash-lite banking, thereby bringing about the cashless economy policy. The major reason is to limit the flow of physical cash in the country. This has made many banks to encourage their customers in making use of e-banking services. However, poor education background of many Nigerians, system efficiency, reliability and security are the major challenges facing this move in Nigeria. These systems need to be highly efficient, secure and easy to use for all Nigerian. This is because to achieve the cashless economy in Nigeria, everybody must be carry along (both those that have poor education background and can still read and write with their native language). Thus in this paper, we have developed a model suitable for implementing indigenous e-banking system in Nigeria. When this system is fully implemented, it will help to encourage more people to make use of e-banking services thereby upholding the cashless economy policy Nigeria.
\end{abstract}

\section{General Terms}

Security, Algorithms, models.

\section{Keywords}

E-banking, Security, Biometric, Indigenous, conceptual model

\section{INTRODUCTION}

We With the recent introduction of cashless economy by the Central Bank of Nigeria (CBN) using the cash-lite banking, most banks in Nigeria has started the introduction and implementation of many e-support systems for making banking transaction with the view of implementing the Central Bank of Nigeria (CBN) cashless economy agenda. However, the absence of secured and reliable e-banking system that can be used by every citizen (both the literate and illiterate) in most Nigeria banks is a serious limitation militating against this new move in Nigeria banking. Meanwhile, usernames, password, signature and PIN have been used to secure e-banking system in Nigeria. But usernames, password, signature and PIN authentication is vulnerable to hacking [19],[10] and are difficult to be used by non-educated citizen. Hence, there is need for a secured and reliable e-banking system using the fingerprint biometric that will help to encourage indigineous e-banking system. Sri and Smt [17] proposed the used of fingerprint biometric for a secured and reliable e-banking services. This was strongly supported by [4], [3] and [9]. This kind of technology will help to improve the e-banking system security, reliability and make it flexible for both the literate and illiterate. It is true that for Nigeria to arrive at the level of cashless economy we must address some major problems that will militate against it. One of such major problem is illiteracy. Meanwhile taking a drastic action in educating our entire citizen both the age ones will be a welcome idea in eliminating this problem. However computer scientists need to work out model of developing indigenous system taking the citizen tribe and common language into consideration. This will help our age mothers and fathers that are illiterate but understand and use their mother's tongue fluently to be able to use e-banking system for making transaction thereby encouraging the cashless economy policy. One major key for the success of this kind of system (indigenous e-banking system) is the use of biometrics (mainly fingerprint) for controlling access to the system before transaction is been made in the user preferred language. With this kind of system the user don't need to remember any account number, Pin number or signature before making his/her transaction. Thus this will encourage every citizen to make transaction in his/her preferred language. Hence, this paper has developed a model for easy implementation of this kind of system. Using this model will assist the implementation of an efficient e-banking system that will be secured, reliable and be easily used by everybody (both the literate and illiterate), thereby encouraging the cashless economy agenda by the CBN.

In this paper, the 2.0 discuss some related studies in this area, the 3.0 discuss the methods used, the 4.0 discuss the resultant model while the 5.0 talk about the conclusion.

\section{RELATED WORK}

Money is the medium of exchange for making payment, settlement of debt and other business obligations. Meanwhile before the introduction of money, trade by barter which is the system of exchanging goods for goods and services for services was the medium of payment before two parties. The introduction of money has help to eliminate the problems associated with the barter history [18]. Money has served as the only medium of payment for a very long time. In the course of time new and interesting system has been introduced. Such a progression is the introduction of electronic payment system that can be found everywhere today in Nigeria banks. Electronic transaction is a new industry which allows people to interact with their banking account via the internet from virtually anywhere in the world [17]. According to [15], e-transaction refers to the automated process of exchanging monetary values among parties in business transaction and transmitting the value over the electronic medium. In [13] it was stated that e-transaction system can be grouped under four major category namely online card payment, online electronic cash, electronic check and smart card based electronic payment system. Knowing fully well that every electronic means of transaction is faced with a lot of security challenges, the electronic payment 
system is not an exemption, this call for the need of strong security in this kind of system. Thus any electronic transaction system must be able to guarantee strong security, privacy, integrity, compatibility, efficiency, convenience, mobility and low financial risk among others which are the characteristics of biometric system [6]. In [15] it was stated that identity theft has been one of the major and most prominent problem in ebanking system. Hence, the need for strong security platform for this system cannot be under estimated.

Introducing e-banking system, the Central Bank of Nigeria $(\mathrm{CBN})$ rolled out the methodologies of moving Nigeria from a cash based economy to a cashless economy through the cashlite policy by introducing several e-payment systems. CBN noted that the aim is to reduce the use of physical cash in the Nigeria economy and encouraging electronic based transaction. It is true that introducing e-banking system in Nigeria will help to curb most of the problems associated with the manual payment system that make our economy to be cash based economy. However, with Nigeria gradually eliminating the long existing cash based economy through e-payment system; Cyber terrorist has started taking advantages of the poor security nature of this system in sabotaging the country effort and aim to use the technology for financial fraud. Some of the major problems of this system are recorded by [12]; [8]; [7]; [5]. Similarly those that are authorized in using the system for transaction cannot be left out for using such system for fraud. Meanwhile many financial analysts have warned these institutions to work out modalities and methodologies in providing strong security for e-banking systems. In [2] it was added that the inadequate of security potentials in e-banking system lead to financial lost in these systems. All this can be solved by introducing biometric as a medium of accessing ebanking services. Biometric fingerprint are unique to every human. They are generations of numerous ridges and valleys on the surface of human figure. A finger print is the flows of ridges patterns in tip of the finger. Among all biometric traits, fingerprint has one of the highest levels of reliability [11]. Meanwhile biometric is the utilization of physiological characteristics to differentiate an individual. It utilizes biological characteristics or behavioral features to recognize an individual. It is a new way to verify authenticity in many transaction systems [16]. Biometric has been used in area like examination screening [1], electronic voting [14] to mention a few. Due to the success recorded in these areas, this paper proposed such system for securing e-transaction Nigeria banks in order to encourage and achieve the cash-lite agenda. Password and card pin are no more enough to authenticate holder identity but biometric measures seems appropriate and secured. Hence, it is a major medium where indigenous ebanking system can be implemented to encourage wider use of e-banking services. This will help to achieve/promote the CBN cashless economy agenda.

\section{METHODOLOGY}

This paper mainly focuses on developing a highly efficient indigenous biometric e-banking system model using human physiological features (fingerprint) to gain access to the system (that will be suitable for both the literate and illiterate) when implemented. The paper presented the system as a conceptual model. It uses prototyping method to design the system as presented in figure 1-3.

\section{DISCUSSION}

The prototype model presented in this paper is to implement a system for securing and providing indigenous biometric ebanking application using fingerprint biometric authentication technique. The system will be implemented using a fingerprint scanner to capture and verify the system user fingerprint. When the verification is successful, the system will provide options to the user on his/her preferred language (e.g. Yoruba, Hausa, Igbo etc) for making transaction. For example when a Yoruba man select Yoruba menu as his preferred option of language, the system will interact with the person using Yoruba till the transaction is completed, update the records and print out transaction details for the person. The model is made simple so that it can easily be understood by system designer/programmer and thereby simplifying the job of implementing such application. Fig. 1 shows the biometric fingerprint enrollment process. In figure 1, when the fingerprint is been captured by the scanner, it will be compress in order to limit the resources needed to process the image captured, then the quality checker module will be called to check the image quality, after a successful check has been done, the feature will be extracted and store in the database. Figure 2 shows the matching system. In figure 2, there is a matching function module that checks if the user (customer that input his/her fingerprint on the scanner) of the system is a legitimate owner of the account, if the system confirm the user, access is allowed else access is denied. Figure 3 is the system prototype. In figure 3, the matching mechanism will perform its system access/denied. If access is granted, it will allow the user to choose the kind of system (either indigenous or normal system) he/she want to make transaction with and perform the transaction based on the selection and print out transaction details to the user. 


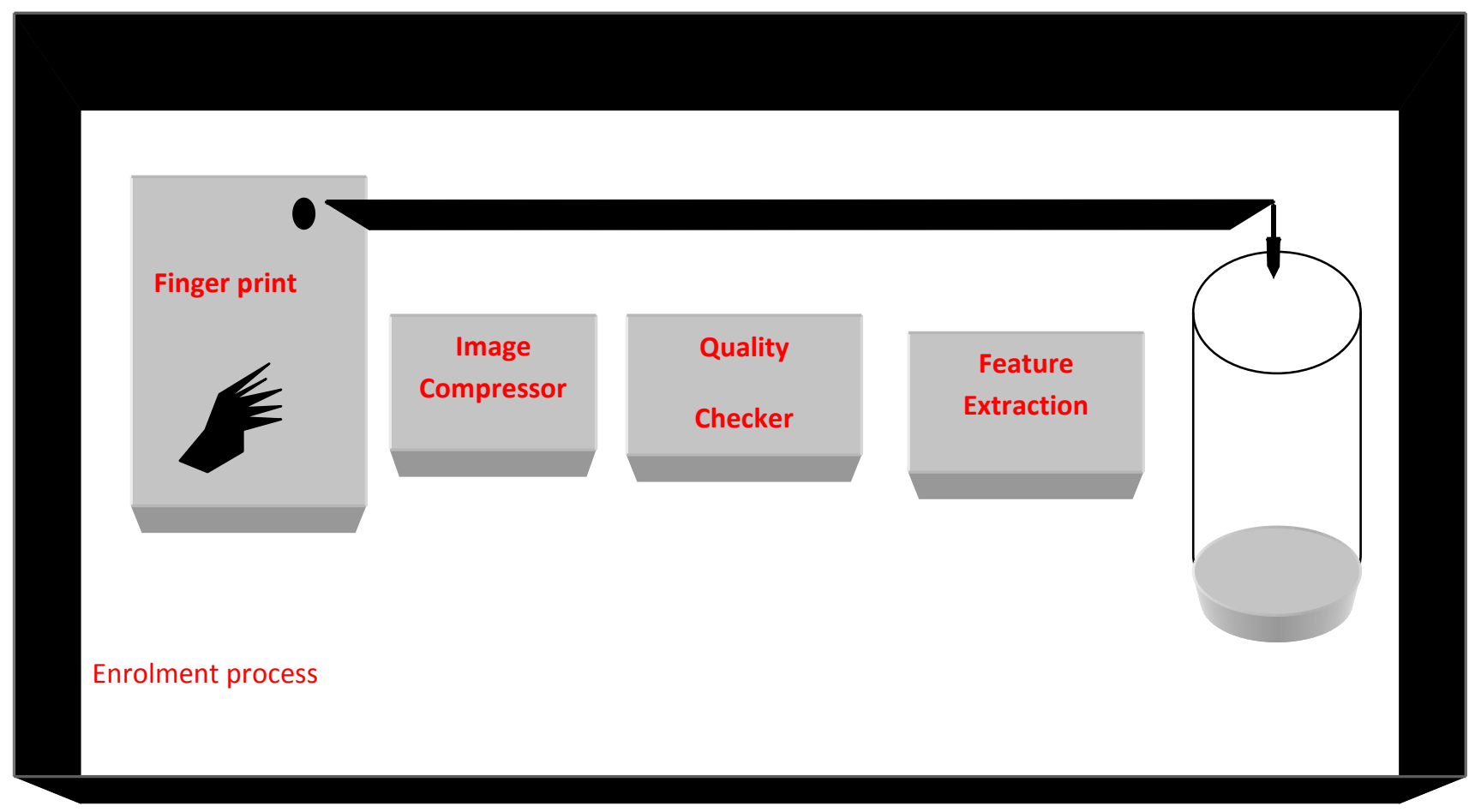

Fig 1: Fingerprint enrolment process

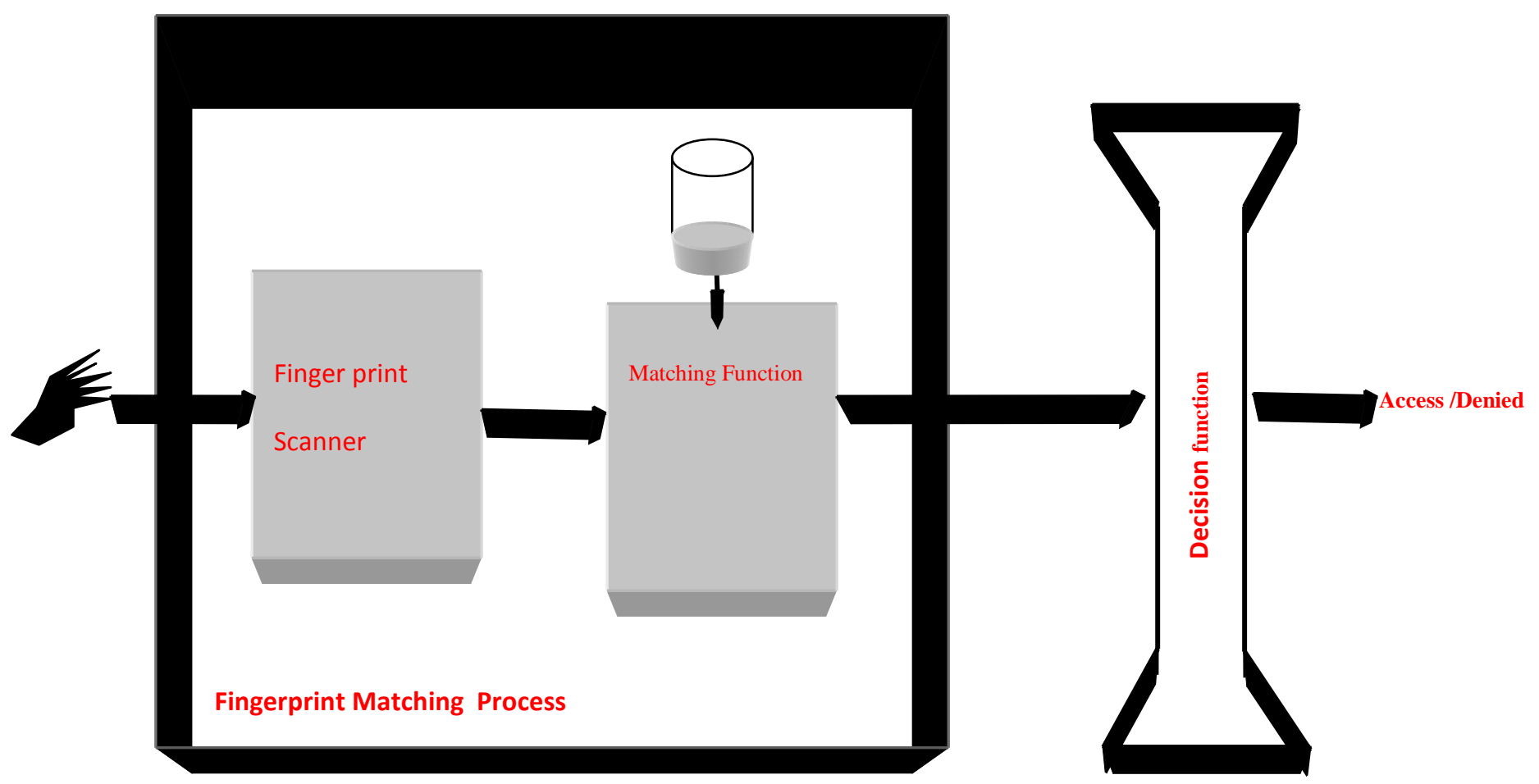

Fig 2: Fingerprint verification process 
Prototype Of The System

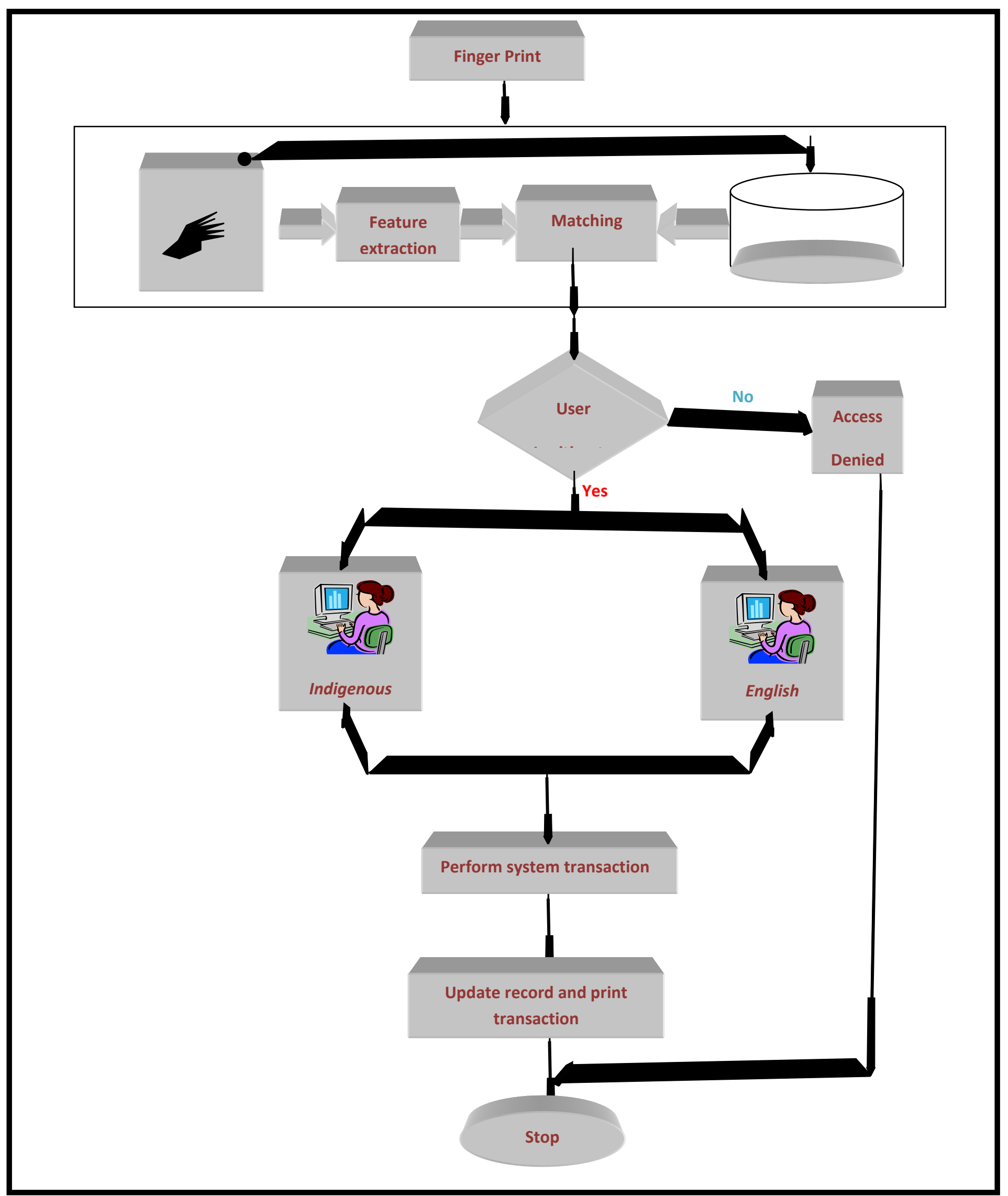

Fig 3: System Prototype 


\section{CONCLUSION}

The cashless economy agenda by the CBN has called the attention of many researchers in developing accurate models that will be suitable in implementing efficient, secured and reliable e-banking system that can be easily used by many Nigerian. Considering the level of educated people in Nigeria, there is no doubt that it will be difficult to achieve cashless economy if improvement is not made in our e-banking systems, since they are the major tools for achieving cashless economy. These improvements are on the context of system security, reliability and accessibility to everybody irrespective of the educational background. Based on these facts this paper recommend a biometric (fingerprint) model for securing and operating e-banking system in Nigeria. Through this, indigenous e-banking system that will be easy to use by many Nigerian irrespective of the educational background can be implemented. Hence, this paper developed and presented a prototype of this kind of e-banking system (indigenous biometric e-banking system) that can be easily implemented. Meanwhile, the full implementation of this model will help to achieve highly secured, efficient, reliable and easy to use indigenous e-banking system by many Nigerian.

\section{REFERENCES}

[1] Adeoye T.O. (2014). Development of a computerized biometric control examination screening and attendance monitoring system with fee management. World of Computer Science and Information Technology Journal Vol. 4. No 6, 76-81.

[2] Ahmad, K.U and Mahmood, H.S (2013) Critical Success Factors for Preventing e-Banking Fraud. Journal of Internet Banking and Commerce. Vol 18, No 2, 1-14.

[3] Akazue M and Efozia N.F (2010). A Review of Biometric Technique for Securing Corporate Stored Data. Proceeding of the Internationa Conference on Software Engineering and Intelligent Systems Vol 1. Pp 329-342.

[4] Akinyemi O.I, Zaccheous O.O and Olufemi M.O (2010). Towards Designing a Biometric Measure for Enhancing ATM Security in Nigeria E-banking System. Internationa Journal of Electrical and Computer Sciences IJECS. Vol 10, No:6, pp 68-73.

[5] Ayo, C.K and Ukpera W.I (2010). Design of a secure unified e-payment system in Nigeria: A case study. African Journal of Business Management Vol. 4(9), pp. $1753-1760$

[6] Biometrika,( 2011). Introduction to Biometric Systems, s.l.: Biometrika (Italy) Available at:http://www.biometrika.it/ eng/wp_biointro.html.

[7] Drygojio, A (2011) Information and Communication Security. LIDIAP Speech processing and Biometric Group. Institute of electrical Engineering. Ecole polytechnique Federalede. http//scgwww.epfl.ch/courses
[8] Fajfar, M (2004). Role and Security of Payment Systems in an Electronic Age. IMF Institute Seminar on Current Development in Monetary and Financial Law in June 2004 Available at www.imf.org/external/np/leg/sem/2004/edmfl/eng/faj.pd

[9] Favour N (2013). CBN to Lunch Biometric Details of banks customers. Nigeria Vanguard Newspaper December 112013.

[10] Jung ho, E (2014) The Design of Robust Authentication Mechanism using User's Biometrics Signals. International Journal of Security and Its Applications Vol.8, No.6, pp.71-80

[11] Keerthi P.P. Deepak R.G. Swathi K. and Rupali N. (2014). Secure Fingerprint Using Mosaicing. IOSR Journal of Computer Science Vol 3. Issues 2. Pp. 73-79.

[12] Marketplace, A (2011) Nigerian Bank Deploys country first biometric ATM. ATM marketplace. Industrial Report on 2015 ATM and Self-Service Software Treads. Available http://www.atmmarketplace.com/article/179366/Nigerian -bank-deploy-country-s-first-biometric-ATM

[13] Mukherjee, A and Nath P. (2003). A model of trust in online relationship banking. International journal of Bank Marketing. 21(1). Pp. 5-15

[14] Olowookere A and Awode T (2014). Design of a Secured Electronic Voting System Using Biometrics. International Journal of Innovative Research in Computer and Communication Engineering. Vol.2, Issues 12 pp 101-106.

[15] Rashmi H. (2015). Biometrics Authentication Technique with Kerberos for Email Login. International Journal of Advances in Engineering and Technology. Vol. 7 (6), pp.1735-1744.

[16] Ruppinder S and Naringer R. (2014). Comparison of Various Biometric Methods. International Journal of Advances in Science and Technology Vol. 2 issue 1.

[17] Sri S.D and Smt J.D (2011). Designing a Biometric Strategy (Fingerprint) Measure for Enhancing ATM Security in Indian E-Banking System. International Journal of Information and Communication Technology Research. Vol.1 No. 5. Pp 197-203.

[18] Taiwo O.A, Tajudeen J.A and Ebeneza Y.A (2011). Electronic Payment System in Nigeria: Implementation, Constraints and Solutions. Journal of Management and Society. Vol. 1, No 2, pp. 16-21.

[19] Vandommele T (2010). Biometric Authentication Today. Available at http://www.csc.hut.fi/en/publications/B/11/papers/vando mmele.pdf. 